\title{
What is the impact of autism on mother-child interactions \\ within families with a child with autism spectrum disorder?
}

Mieke Meirsschaut $^{\mathrm{a}} *$

Petra Warreyn ${ }^{\mathrm{a}}$

Herbert Roeyers $^{\mathrm{a}}$

Running title: Interactions in a family with a child with ASD

\footnotetext{
${ }^{a}$ Research Group Developmental Disorders, Ghent University, H. Dunantlaan 2, B - 9000, Ghent, Belgium

* Corresponding author: Research Group Developmental Disorders, Ghent University, H. Dunantlaan 2, B 9000, Ghent, Belgium, Mieke.Meirsschaut@arteveldehs.be, Tel.: +32(0)9-2649414; Fax: +32(0)9-2646489.
} 


\section{Lay Abstract}

In this study, we investigated whether having a child with autism spectrum disorder (ASD) has an impact on the way mothers interact with their other child(ren) without ASD. Mothers were observed during a play and a task interaction separately with their child with ASD (between 4 and 7 years old) and with a younger sibling without ASD (between 2.5 and 5.5

years old). We wanted to find out if mothers were different in how they interacted with their child with ASD compared to their non-ASD child. We also compared the social behaviour of the two children. Mothers seemed to respond more often to the initiatives of their non-ASD child, but they interacted equally much with both their children. The children with ASD demanded more (help or objects) from their mothers, but there were no other differences between the children. After discussing possible explanations for our findings, we conclude that family-based therapy may benefit from a better understanding of the way mothers and children interact in families with a child with ASD. 


\section{Scientific Abstract}

This within-family study investigated whether mothers differentiate between children in their interactive behaviour. Mothers were observed during a play and a task interaction separately with their child with autism spectrum disorder (ASD) (between 46 - 84 months old, $M=68$ ) and with a younger sibling (between 29 - 67, M=48). Additionally, the social behaviour of the children with ASD and their Non-ASD siblings was compared. Results show that mothers differentiated in their responsiveness but not in their initiatives towards the children. Children with ASD and their Non-ASD siblings were equally responsive but children with ASD were more imperative toward their caregiver. Several interpretations of these findings are discussed. Finally, it is concluded that family-based interventions will benefit from a better understanding of the effect of ASD on mother-child interactions within families with a child with ASD. Therefore, between-family studies should be complemented with within-family studies.

Key words: within-family design, mother-child interaction, Autism spectrum disorder 


\section{Introduction}

Research has shown that the severe and pervasive impairments in communication and social interaction and the maladjusted behaviour in children with autism spectrum disorder (ASD) are a significant source of stress and depressive symptoms for parents of a child with ASD (Eisenhower et al., 2005; Estes et al., 2009; Montes \& Halterman, 2007; Olsson \& Hwang, 2001; Rao \& Beidel, 2009). These impairments and the stress involved also have a considerable impact on parent’s interactive behaviour (Hoppes \& Harris, 1990; Kasari \& Sigman, 1997). There is evidence that parents of a child with ASD adopt a different interaction style compared to parents of typically developing (TD) and developmentally delayed (DD) children, possibly in an attempt to compensate for the social limitations of their child (Kasari \& Sigman, 1997; Meirsschaut et al., 2011). In order to get higher engagement and responsiveness from their child, parents of a child with ASD use more directive strategies (Spiker et al., 2002; Meirsschaut et al., 2011), spend more time physically holding their child on a task and increase their physical proximity more during interaction (Kasari et al.,, 1988; Lemanek et al., 1993). Compared to parents of DD- and TD-children, parents of children with ASD also show more high intensity approach behaviours to get their child's attention (Doussard-Roosevelt et al., 2003; Lemanek et al., 1993).

A number of studies have examined the effect of a child with ASD on mother-child interaction and on mothers' interactive behaviour, but almost all of these studies have compared mother-child interaction between families (e.g., Hoppes \& Harris, 1990; Kasari \& Sigman, 1997; Kasari et al., 1993; Rutgers et al., 2007). Little is known, however, about the effect of ASD on the dyadic interactions within a family with a child with ASD. For a deeper understanding of the effect of ASD on family interactions it is important to evaluate whether 
mothers differentiate in their interactive behaviour towards affected and non-affected siblings or whether they generalise their autism-adapted interaction style across interactions.

Sibling research in in developmental psychology has revealed that parents do not treat siblings within the same family identically (Dunn et al., 1986; Rivers \& Stoneman, 2008). Differential parental treatment refers to the differences in parenting as experienced by siblings within families, including domains such as parental warmth, responsiveness and controlling behaviour, parents' temporal involvement, the allocation of household tasks, etc. It is even more likely in families with a child with a disability or a chronic illness (Corter et al., 1992; McHale \& Pawletko, 1992; Quittner \& Opipari, 1994) because of the more extreme differences in abilities and needs between siblings with and without a disability. In these families, differential parenting may take the form of unequal distribution of time and attention in favour of the sibling with a disability (McHale \& Pawletko, 1992) and relatively stricter disciplinary strategies and more involvement in household tasks for the TD sibling (McHale \& Gamble, 1989).

However, besides this significant evidence of differential treatment within families, some researchers also found similarities in mother's interactions with their different children (Corter et al., 1983; Corter et al., 1992; Dunn et al., 1986). Corter and colleagues (1983), for example, found that mothers were consistent both in negative and positive behaviours towards younger and older siblings. Dunn et al. (1986) concluded that mothers show different verbal, controlling and affectionate behaviour towards the same child at different ages but that they are consistent in their behaviour towards their different children when they are the same age.

To our knowledge, the study of Doussard-Roosevelt and colleagues (DoussardRoosevelt et al., 2003) is the only published study that examined differential parenting within ASD families. The comparison of the mother-child interactions within 9 families with a child with ASD and a TD child revealed that mothers did not differ in the number of approaches, 
but that they used fewer social verbal approaches and more physical contact towards the child with ASD than towards their TD child. In line with the main findings of the general sibling literature, these authors concluded that mothers adapted their behaviour within each motherchild interaction based on the characteristics of the specific child.

Replication and extension of these within-family findings is clearly needed to clarify the interpretation of the between-family differences of mother-child interaction in ASD and TD families (Plomin et al., 2001). A deeper understanding of the effect of ASD on motherchild interactions is necessary for the development of more supportive family-based autism interventions. In the present study, we test the hypothesis that mothers differentiate in their interactive behaviour towards their child with ASD and their non-ASD child. Several questions will be explored: Firstly, we want to know whether there is a difference in the frequency and function of the social initiatives mothers direct towards their child with ASD versus their non-ASD child. Based on previous between-family research (Lemanek et al., 1993; Meirsschaut et al., 2011), we expect mothers to take more initiatives towards their child with ASD than towards their non-ASD child. Additionally, it is expected that mothers' initiatives are more directive or imperative with their child with ASD and more non-directive or declarative with their non-ASD child. Secondly, we will explore if there is a difference in mothers' rate of responsiveness towards her ASD- and non-ASD child. Based on the limited amount of available literature concerning this topic (e.g. van IJzendoorn et al., 2007), we do not expect to find differences.

Since context of social interaction may also have an influence on social behaviour, mother-child interactions will be compared in a less structured context of free play and in a more structured task context. Based on previous between-family research (Landry et al., 1994) the differences in the frequency and function of mothers' social initiatives towards their child with ASD and their non-ASD child are expected to be more apparent in the play context 
than in the task context. In the task context, mothers probably will be equally directive with both children, because of the increasing cognitive demands of the situation. In the unstructured play context, by contrast, mothers may use more directive strategies with their child with ASD in an attempt to provide this child with the necessary support and structure. For context-related differences in maternal responsiveness, there is no literature available to base expectations upon.

However, mother's social behaviour does not develop in isolation, but within the dynamic context of each particular parent-child interaction (Bell \& Chapman, 1986; DeaterDeckard et al., 2005). For the correct interpretation of mothers' behaviour directed towards their child with ASD and towards their non-ASD child, an evaluation of the children's social behaviour is essential. Furthermore, given the elevated rates of mild characteristics of autism in siblings of children with ASD, referred to as the broader autism phenotype (Dawson et al., 2002; Murphy et al., 2000), it is important to compare the social behaviour of the children with ASD and their Non-ASD siblings. Therefore, we firstly evaluated whether children with ASD differ from their Non-ASD siblings in frequency and function of initiatives addressed towards their mother.

We expected children with ASD to use fewer social initiatives but to be more imperative in their initiatives than the non-ASD siblings because of their well-known social and communicative impairments (Dawson et al., 2004; Stone, Ousley, Yoder, Hogan \& Hepburn, 1997; van IJzendoorn et al. 2007; Wetherby, Watt, Morgan, \& Shunway, 2007; Wimpory et al., 2000; for a review see Bruinsma, Koegel, \& Koegel, 2004; Mundy, Sullivan, \& Mastergeorge, 2009).

Secondly, based on previous research concerning the responsiveness of children with ASD, we expected children with ASD to react less responsively to mothers’ initiatives in comparison to their non-ASD siblings (Adamson et al., 2001; Jackson et al., 2003; 
Willemsen-Swinkels et al., 1997). We expected these differences in initiatives and responsiveness to be more apparent in the play context because children with ASD especially experience difficulties in unstructured situations (Landry et al., 1994).

\section{Method}

\section{Participants}

Sixteen mothers with a child with ASD and with a child without ASD participated in this study. The families were recruited through local rehabilitation centres. The children with ASD ranged in age from 46 to 84 months $(M(s d)=68(11.56))$. Their youngersiblings without ASD ranged in age from 29 to 67 months $(M(s d)=48(13.02))$. We chose to include only families where the non-ASD sibling was the younger one of the two children, in order to have comparable developmental levels between both children and thus to maximize homogeneity in the collected data. The non-ASD child was on average 20 months younger than the ASD sibling ( $s d=7.00$ ). There was a predominance of boys in our sample, with 6 'brother-brother’ dyads (ASD - non-ASD), 7 'brother-sister’ dyads, 2 ‘sister-brother’ dyads and one 'sister-sister' dyad. A chi-square analysis showed no significant difference in sex ratio between the ASD and the non-ASD group $\left(X^{2}(1)=1.25, p=n s\right)$. Both the children with and without ASD were pre-screened for ASD with the Social Communication Questionnaire, lifetime version (SCQ; Rutter et al., 2003; Dutch translation by Warreyn et al., 2004). The SCQ is a parent questionnaire, consisting of 40 dichotomous questions, derived from the Autism Diagnosic Interview-Revised (ADI-R; Rutter, Le Couteur, \& Lord, 2003). The recommended cut-off score for children aged 4 years and older is 15 . For families to be included in the study the SCQ scores of the child with ASD and of the non-ASD sibling had to differ with at least 5 points. This permitted to verify whether the mothers reported significantly more ASD symptoms in their child with ASD than in their non-ASD child, 
according to the child's diagnostic status. All the children with ASD had received a clinical diagnosis of ASD after an extensive diagnostic procedure by an experienced multidisciplinary team, prior to the study. Since some of these children had received several years of treatment prior to this study, not all children with ASD scored above the SCQ cut-off of 15 (4 children obtained a score between 10 and 15). If there was any doubt about the diagnostic status of a sibling, e.g., because of a sub-threshold score on the SCQ $(n=4)$ or because of concerns by the parent $(\mathrm{n}=1)$, an additional Autism Diagnostic Observation Schedule (ADOS; Lord et al., 1999) was performed. Accordingly, two families were excluded from the initial study group ( $n=18$ ) because of a sub-threshold score of the sibling on the ADOS. The other two siblings, who both had an SCQ score of 10, showed good social-communicative skills on the ADOS, and were therefore included in the final sample. The mean SCQ difference score was 14.43 (sd = 6.93; range $6-28$ ). The nonverbal intellectual functioning of each child was assessed with a short form of the Snijders-Oomen Non-verbal Intelligence test $2^{1 / 2}-7$ (SON-R; Tellegen et al., 1998). The SON-R requires no use of written or spoken language, and is therefore especially suitable for , amongst others, children with hearing problems, language disorder, autism, or a different cultural background. It yields a performance IQ, a reasoning IQ, and a total nonverbal IQ. Word comprehension was measured with the Peabody Picture Vocabulary Test-III-NL (PPVT-III-NL; Dunn \& Dunn, 2005). See Table 1 for details of the sample. [insert Table 1 about here]

A one-way analysis of variance (ANOVA) revealed no significant differences in developmental age or in word comprehension between children with ASD and their non-ASD siblings. According to the SON-R (Tellegen et al., 1998), about $69 \%$ of the children with ASD functions within the normal developmental range. In the non-ASD group, about $81 \%$ obtained scores within the normal developmental range. The PPVT-III-NL (Dunn \& Dunn, 2005) showed that about $63 \%$ of the children with ASD and $74 \%$ of the non-ASD siblings 
obtained a non-clinical score for word comprehension. However, the limited sample size of our study restricts the power of analysis. Therefore, one should be cautious in interpreting these results. Furthermore, similarities in absolute level of children's developmental functioning and word comprehension do not automatically correspond to similar meaning of the developmental and language levels to the mothers.

Mothers ranged in age from 27 to 47 years $(\mathrm{M}(\mathrm{sd})=33.87(4.77)$. Their social status ranged from 27 to $53(\mathrm{M}(\mathrm{sd})=42.88(8.11))$ The social status score, ranging from 8 to 66 , is a weighed score taking into account both occupation and education of an individual. (Hollingshead, 1975). Hollingshead defined 5 social strata, the scores in our sample correspond to the middle 3 strata, reflecting an average social status. All but two families were two-parent households.

\section{Procedure}

For this study, a mother and both of her children were invited in a neutral university lab for an observation of the mother-child interaction. Mothers were told that the focus of observation was how their child acted in a play and task situation. They were asked to interact with their child like they usually would. Mothers were observed during a less structured play interaction (7 minutes) and during a more structured task interaction (7 minutes) with their child with ASD and consequently with their non-ASD child (or vice versa). Before the free play, mother and child were shown the play material and were asked to play the way they preferred. For the task interaction, mother and child were given a box of blocks and were instructed to build as many block constructions as fast as possible, from a book of construction photos. This book consisted of 21 photos of constructions with blocks, with an increasing level of difficulty. It was explicitly mentioned that mothers could help their child. 
While one child was being observed with the mother, the other child was tested for language comprehension with the PPVT-III-NL (Dunn \& Dunn, 2005) by a research assistant. The research assistant was a postgraduate psychology student who was trained and supervised in test administration. She was blind for the diagnosis of the child. Two observational sequences were counterbalanced: in half of the cases mother was first observed with her child with ASD and next with her non-ASD child and for the other half of the cases the sequence was reversed. Accordingly, we provided two comparable sets of toys for the play interaction and two comparable sets of blocks and photo books for the task interaction. After the play- and task interaction, a short form of the SON-R (Tellegen et al. , 1998) was administered by the research assistant for both children separately, while mother was interviewed by the first author about her parenting experiences and cognitions towards her child with ASD and her non-ASD child. The results of these interviews are reported elsewhere (Meirsschaut et al., 2010). Prior to the observation, mothers completed an informed consent and a sociodemographic form.

\section{Coding Procedure, - Behaviour and Interobserver agreement}

All mother-child interactions were recorded digitally. Only the middle 5 of the 7 minutes of mother-child interaction were coded. Two research assistants (postgraduate psychology students), blind to the diagnosis of the children, coded the social behaviour of mother and children, using the observer XT, version 8.0 (Noldus, 2008). Coders were trained in the use of the behavioural coding system using several practice tapes of children not included in the study. The first author provided the criterion against which the coder's performance was compared. Training on the practice tapes continued until the coder's degree of agreement with the criterion reached an acceptable standard. For both mother and child the frequency of the following elements was coded: 
A) social initiatives, defined as an attempt to interact with someone. This can be verbal and/or non-verbal (e.g. pointing, showing, or seeking physical proximity combined with eye contact) and is always addressed to a person with the intention to get a response from that person. For each social initiative the content must be defined. This can be declarative (or social, to share interest in something with someone, e.g. "I'll feed the doll”), imperative (or directive, to request something from someone, e.g. "Put that away!"), or neutral (no clear declarative or imperative intention, e.g. “Ok, what’s next?”). B) social responses, defined as a reaction to a social initiative or response and following the preceding attempt within $3 \mathrm{~s}$. It can be verbal and/or non-verbal and is always addressed to the other person. For each social response the content must be defined. This can be confirming (when the response confirms the preceding initiative or response, e.g., “Yes, good idea!”), non-confirming (when the response denies the preceding initiative or response, e.g., "No, she is not hungry”), or neutral (when the response is not clearly confirming or denying, e.g., “mmh”). For the responses of the child a fourth category was included to code children's unsuccessful responses to comply: attempt to comply (e.g., "I don’t know” as a response to mother’s question "What colour is this?”). The full coding scheme can be obtained upon request from the first author. About $15 \%$ of the mother-child interactions were randomly selected for double coding for purposes of interobserver agreement. Kappa was .81 (range .70 - .90) for child’s and mother’s behaviours, i.e., the social initiatives and responses. Kappa was .74 (range .61 - .85) for agreement in coding of the content (e.g., declarative versus imperative initiative and confirming versus non-confirming response) of child's and mother's behaviour.

\section{Results}

For all mother- and child- variables, assumptions for parametric analyses were met. Mother’s social behaviour was analyzed by means of ANOVA's repeated measures, with 
diagnosis of the child (ASD versus non-ASD) and context (play versus task) as withinsubjects factors. Child's social behaviour was analyzed by means of ANOVA's repeated measures, with diagnosis of the child as between-subjects factor and context as withinsubjects factor. An additional paired-samples t-test was performed to examine if the content of mothers' initiative had an effect on children's responsiveness. Since children with ASD and their younger non-ASD siblings differed significantly in age, analyses of covariance with children’s age entered as a covariate have been considered. However, no significant correlations were found between children's age and mothers' or children's social initiatives or responsiveness, and therefore analyses of covariance were considered not appropriate. Mothers' social behaviour towards their child with ASD and towards their non-ASD child in a play versus task context

Social initiatives. There were no significant effects of diagnosis or diagnosis*context for the frequency of mothers' initiatives, but the effect of context shows that mothers initiated significantly more in the task context compared to the play context. Similar results were found for the content of mothers' initiatives. Mothers directed comparable proportions of declarative and imperative initiatives towards their child with ASD and their non-ASD child. Again, there was a significant effect of context with more declarative initiatives in the play context and more imperative initiatives in the task context. The results are presented in Table 2. [ Insert Table 2 here]

Responsiveness. As a measure for mothers' responsiveness, we calculated the proportion of a child's social initiatives followed by a reaction of the mother (within 3 s). Significant main effects of diagnosis and context were found. As shown in Table 2, mothers reacted significantly more responsively to their non-ASD child compared to their child with ASD. Additionally, mothers showed a significantly higher responsiveness during the task than during the free play. Analysis of the content of responses revealed no significant differences 
in proportion of mothers' confirming, non-confirming and neutral responses towards both their children. There was, however, a significant effect of context for non-confirming and neutral responses. Mothers' responses were more non-confirming in the task context and more neutral in the play context.

The social behaviour of children with ASD and of non-ASD children, in a play versus task context

Social initiatives. As can be seen in Table 3, there were no significant effects of diagnosis or diagnosis*context for the frequency of initiatives in the ASD and non-ASD group, but the frequency decreased significantly from the play to the task context. Analysis of the proportion of declarative, imperative and neutral initiatives revealed that children with ASD used significantly more imperative initiatives while non-ASD children used significantly more declarative initiatives. Both groups used comparable amounts of neutral initiatives. Additionally, a significant effect of context revealed that the proportion of declarative initiatives was significantly higher in the task context. Neutral initiatives tended to be used more in the play context.

[ Insert Table 3 here]

Responsiveness. No significant effect of diagnosis or diagnosis*context was found for children's total responsiveness, but a trend for a context-effect revealed that children tended to react less responsively to their mothers' social attempts in the task context compared to the play context. Similarly, children’s responses were significantly more non-confirming during the task than during play. There were no other significant effects of diagnosis, context or diagnosis*context for the content of children's responses. An additional paired-samples t-test was performed, to examine if the content of mothers' initiative had an effect on children's responsiveness. The results show that the responsiveness of children with ASD to a declarative $(\mathrm{M}(\mathrm{sd})=.28(.20))$ or imperative initiative $(\mathrm{M}(\mathrm{sd})=.29(.15)$ was comparable in 
the task context $(\mathrm{t}=-.21 \mathrm{p}=\mathrm{ns})$. During play interaction, however, they reacted significantly less responsively to a declarative initiative $(\mathrm{M}(\mathrm{sd})=.28(.12))$ than to an imperative initiative $(\mathrm{M}(\mathrm{sd})=.37(.13) ; \mathrm{t}=-2.35, \mathrm{p}<.05)$. By contrast, non-ASD children showed no significant difference in responsiveness to declarative and imperative initiatives in the play $(\mathrm{M}(\mathrm{sd})=.35$ $(.21) ; \mathrm{M}(\mathrm{sd})=.37(.23) ; \mathrm{t}=-.20, \mathrm{p}=\mathrm{ns})$ and task context $(\mathrm{M}(\mathrm{sd})=.32(.20) ; \mathrm{M}(\mathrm{sd})=.29(.10)$; $\mathrm{t}=.43, \mathrm{p}=\mathrm{ns})$.

\section{Correlations of difference scores.}

To explore possible reasons for mothers' interaction styles, we correlated several difference scores. Within each dyad, a difference score was computed of mothers' initiatives and responses by subtracting the sibling score of the ASD score. Similarly, we calculated the difference in age, SCQ-score, estimate of nonverbal mental age (SON IQ*age/100; the SON$\mathrm{R}$ does not yield an age equivalent when not all subtests are administered), and estimate of verbal mental age (WBQ score*age/100). Although we are aware that the latter two estimates are not reliable enough to assess the developmental age of the child, we do believe that they may be used to roughly estimate the developmental difference between the two children in each dyad. The age difference between the two children was significantly negatively related to the difference in mothers' number of initiatives $(r=-.55, \mathrm{p}<.05)$, non-confirming responses $(r=-.50, \mathrm{p}<.05)$, neutral responses $(\mathrm{r}=-.69, \mathrm{p}<.01)$ and positively to the difference in number of her complying responses $(r=65, \mathrm{p}<.01)$. Similar correlations were found with the nonverbal mental age difference score (correlation with mothers' number of initiatives $r=-.65, p<.01$ ) and the verbal mental age difference score (correlation with mothers' number of initiatives $r=-.69, \mathrm{p}<.01$, with complying responses $r=.52, \mathrm{p}<.05$ ). There were no significant correlations with the SCQ difference score (all $r<$.30).

\section{Discussion}


In the present study, we investigated mothers' interactive behaviour towards their child with ASD and their non-ASD child in a play- and task-context and we compared the children's social behaviour. For mothers’ social behaviour, we expected a difference in frequency and function of initiatives towards their child with ASD and their non-ASD child, but not in responsiveness. The results, however, show the opposite: Mothers did not use significantly more social initiatives or more directive initiatives with their child with ASD than with their non-ASD child. In addition, mothers did differentiate in their responsiveness with a higher responsiveness towards the non-ASD sibling. For the comparison of the children's social behaviour, we hypothesized that children with ASD would use fewer social initiatives but more imperative strategies and that they would be less responsive than their non-ASD siblings. Contrary to the expectations, there were no differences in frequency of initiatives and in total responsiveness but, as expected, children with ASD were significantly more imperative compared to their non-ASD siblings. Only for the children with ASD responsiveness tended to vary depending on the content of mother's initiative: mother's declarative initiatives during play interaction were less likely to be followed by a response than her imperative initiatives. Finally, both in mothers and in children, a significant effect of context was found. While mothers were more active and responsive during the task, children to the contrary initiated and responsed less during the task. No interaction effects of context*diagnosis were found.

These results contradict a substantial part of our hypotheses. It is, however, important to mention that these hypotheses were derived from previous between-family results. Apparently, one should be cautious in extending the findings of between-family studies to within-family interactions. The finding that mothers did not significantly differentiate in their number of social initiatives towards both children is in line, though, with what DoussardRoosevelt and colleagues (2003) reported in their within-family study. Based on the 
differences in maternal verbal approaches and in physical contact they found between the two children, they concluded that mothers adjust their social behaviour specifically to the characteristics of their different children. However, we cannot compare all our results with those of Doussard-Roosevelt et al, since we restricted the coded behaviours to the ones used in a previous study (Meirsschaut et al., 2011), in order to keep results comparable. Furthermore, there are also some methodological limitations in the study of DoussardRoosevelt and colleagues: They did not include a measure for mothers' responsiveness, nor did they report on the children's social behaviour. Furthermore, only a small sample of 9 mothers with both their children was included and it is not clear, from the limited description of subjects and procedure, how children with ASD and non-ASD siblings differed in age at the time of observation.

Since we carefully verified that the non-ASD siblings in our sample indeed could not be suspected of having ASD, the lack of differences between the two children cannot be explained by the possibility that both groups included children with ASD. Although we cannot exclude the possibility that the lack of significant group differences is mainly due to the small sample size, we believe that it may, at least partly,have other causes.

Firstly, in 14 out of the 16 families in our study, the child with ASD was mother's first born child. Hence, this child determined the mothers’ first parenting experience. Perhaps mothers generalized this interaction style to their younger child. This interpretation is consistent with the notion that parents learn from the childrearing experience with their first child, as concluded by Whiteman and colleagues (Whiteman et al., 2003).

A second interpretation is that mothers (consciously or not) adopted their autism-interaction style also with their non-ASD child, because they recognized similar behaviour in their nonASD child (i.e., broader phenotype autism symptoms; see e.g., Dawson et al., 2002) as in their child with ASD and therefore they belief that their non-ASD child also benefits from a more 
active and directive interaction style. A third possible interpretation is that mothers did not differentiate their behaviour because they were dealing with only one child at the time during the observation. It is very likely that interactions taking place in the context of a dyad differ from triadic interactions (Corter et al., 1983; McHale, 2008). Furthermore, we cannot rule out the effect of observation on mother's social behaviour. It is possible that mothers, intentionally or not, showed similar behaviour to show both of their children at their best. Similarly, for the interpretation of the children's behaviour, reactivity to observation cannot be dismissed.

Finally, since all non-ASD children in our study were younger than their ASD siblings, it is possible that mothers used a specific interaction style with both their children for different reasons. Perhaps mothers were more active and directive with their oldest child because of his/her ASD-characteristics and with their youngest child because of his/her lower developmental abilities, as a consequence of the younger age. This alternative explanation of mothers’ similar interaction style with both her children was explored by correlating difference scores. Further visual exploration of these correlations using box plots suggested a maternal interaction style of using many initiatives, non-conforming and neutral responses, and less complying responses, possibly reflecting a directing and correcting interaction style. If there was a large age difference (mainly chronological, but also verbal or nonverbal) between both siblings, this interaction style was more used with the younger (non-ASD) siblings. If the age difference was smaller, however, this interaction style was directed more to the ASD sibling. These results may suggest that mothers mainly adopt their interaction style to the developmental level of their children (which is also suggested by Marfo, 1992), and perhaps less specifically to the autism characteristics (which may be interpreted by mothers as some kind of delay). This may also explain the majority of differences between the current study results and previously reported studies: our groups by definition differed in age, 
while this was not the case in previous studies. In contrast to the consistency in the initiatives mothers directed at their both children, we did find a differentiation in maternal responsiveness. The unexpected higher responsiveness mothers showed towards their nonASD child was not related to any of the child characteristics or differences scores. There was also no effect of content of the child's initiatives on mother's responsiveness, as shown by an additional paired-samples t-test.

Perhaps mothers reacted less responsively to their child with ASD because they expected more independent behaviour during the play and the task from their older child, despite the ASD. Indeed, concerning the task, some of the mothers mentioned afterwards that they found it quite difficult for their youngest (non-ASD) child.

The comparison of the mother-child interactions in a less and more structured context revealed that mothers changed their social behaviour depending on the context, which is in line with previous between-family research (Landry et al., 1994). We found that mothers were more active and more directive during the task and they were also significantly more responsive and more non-confirming in their responses. These results suggest that mothers were sensitive to the context of social interaction. Mothers seemed to adapt their social behaviour to the more demanding context of the task, in order to provide both their children with the necessary support to show the full potential of their ability. Since we found no interaction effects of diagnosis of the child with context, one can conclude that mothers did not differentiate between children in their contextual adjustment, which is in contrast to our expectations. Again, however, these were based on between-family results (Landry et al., 1994).

For children’s social behaviour, the effect of context seems to be reversed: Both children with and without ASD initiated less during the task, used proportionally more declarative 
initiatives and reacted less responsively. Like their mothers, children were more nonconfirming during the task. These context-related changes in children's behaviour suggest that both children with and without ASD were sensitive to the demands of the context. The contextual adjustments can be interpreted as a result of both children becoming equally absorbed in the task, since no interaction effect of diagnosis with context was found.

In sum, the comparison of mothers' social behaviour towards their child with and without ASD has revealed both differences and similarities. Mothers did not differentiate in their initiatives towards their child with ASD and towards their non-ASD child, but they differentiated, on the other hand, in their responsiveness towards their different children. Although our results suggest that mothers' interaction style may be more adapted to their children's age and developmental level, and less related to the number of ASD-symptoms, more within-family research is clearly needed. One of the most important conclusions of this study is that one cannot simply extend results of between-family comparisons to withinfamily interactions. We totally agree with Plomin and colleagues (2001) that consideration of within-family variation is necessary for a more comprehensive understanding of the motherchild interactions, especially in more complex situations such as in families with a child with ASD. Likewise, more within-family comparisons of siblings' social behaviour will facilitate the interpretation of the differences and similarities we found between children with ASD and their non-ASD siblings.

In the context of family-based autism interventions, especially the finding that mothers are less responsive towards their child with ASD seems to be highly relevant. However, both in typically developing children as in children with ASD, it has been found that higher levels of maternal responsiveness are predictive of children's better language abilities several years later (Siller \& Sigman, 2002; Taylor, Anthony, Aghara, Smith, \& Landry, 2008). In addition, research suggests that increasing maternal responsiveness through intervention has a stronger 
beneficial effect on children with ASD than on children with, e.g., a developmental delay (Mahoney \& Perales, 2005). Therefore, it seems especially important to stimulate mothers to be highly responsive when interacting with their child with ASD, and not only - although this may be easier - when interacting with their non-ASD child(ren). Furthermore, the rather high variability in interaction style that was apparent in our group of mothers, stresses the need for a careful assessment of parent-child interactions at the start of a family-based intervention. Helping parents to adopt an interaction style that is optimal for their child with autism, will not only help the child itself, but may also decrease parental stress and increase parental feelings of competence and efficacy (Keen, Couzens, Muspratt, \& Rodger, 2010).

Finally, some limitations and suggestions for future research should be noted. A first limitation of this study is the lack of a control group of typically developing (TD) families. Although - as mentioned above - quite some research has investigated differential parenting in typical families as well as families with a child with a disability, most of this research has focused on variables such as positivity/negativity, controlling and disciplinary strategies, involvement in household tasks, ... . Therefore, we cannot directly compare the results of our study to the information obtained in previous studies. Comparison of the dyadic interactions, using a detailed coding scheme including time, form, and function of every initiative and response within families with a child with ASD and within TD families will clarify the interpretation of our within-family findings. A second limitation is the relatively small sample-size with only younger non-ASD siblings included. This small sample-size limits power and constrains the ability to use for instance multi-level modelling, in which siblings could be nested within families. To clear out the effect of birth-order, future studies should adopt a larger and mixed sample, with both younger and older non-ASD siblings of children with ASD. Additionally, since Dunn et al. (1986) found that mothers' social behaviour is consistent towards their different children when they have the same age, it would be very 
interesting to evaluate mothers' interactive behaviour towards their child with ASD and their non-ASD child over time with a longitudinal study.

Although the distribution of boys and girls in our groups was not significantly different, we explored whether there were significant differences between the girls and boys in the entire sample. This was not the case, and all effect sizes (expressed in partial eta squared) were below .15 (while .20 indicates a small effect size, Cohen, 1992). However, to reduce the amount of noise possible masking significant group differences, it would be more ideal to have both groups matched on gender .

Another interesting pathway for future within-family research is to observe mothers' and children's interactive behaviour during triadic interaction, with both siblings present. As Corter and colleagues (1983) already suggested observation of mothers' social behaviour with both children present perhaps shows a ecologically more valid picture of how mothers differentiate between their children in daily life. Following McHale and colleagues (2008), similarly, observing the triadic interaction between the child and both of its parents simultaneously may be equally interesting. 


\section{References}

Adamson, L.B., McArthur, D., Markov, Y., Dunbar, B. \& Bakeman, R. (2001). Autism and joint attention: Young children’s responses to maternal bids. Journal of Applied Developmental Psychology, 22, 439-453.

Bell, R.Q., \& Chapman, M. (1986). Child effects in studies using experimental or brief longitudinal approaches to socialization. Developmental Psychology, 22, 595-603.

Corter, C., Abramovitch, R., \& Pepler, D.J. (1983). The role of the mother in sibling interaction. Child Development, 54, 1599-1605.

Corter, C., Pepler, D., Stanhope, L., \& Abramovitch, R. (1992). Home observations of mothers and sibling dyads comprised of Down's syndrome and nonhandicapped children. Canadian Journal of Behavioural Science, 24, 1-13.

Dawson, G., Webb, S., Schellenberg, G., Dager, S., Friedman, S., Aylward, E., et al. (2002). Defining the broader phenotype of autism: Genetic, brain and behavioral perspectives. Development and Psychopathology, 14, 581-611.

Doussard-Roosevelt, J.A., Joe, C.M., Bazhenova, O.V., \& Porges, S.W. (2003). Mother-child interaction in autistic and nonautistic children: Characteristics of maternal approach behaviours and child social responses. Development and Psychopathology, 15, 277295.

Dunn, L.M., \& Dunn, L.M. (2005). Peabody Picture Vocabulary Test-III-NL, Nederlandse versie Liebeth Schlichting, Harcourt Assessment B.V., Amsterdam.

Dunn, J.F., Plomin, R., \& Daniels, D. (1986). Consistency and change in mothers’ behaviour toward young siblings. Child Development, 57, 348-356.

Eisenhower, A.S., Baker, B.L., \& Blacher, J. (2005). Preschool children with intellectual disability: syndrome specificity, behaviour problems, and maternal well-being. Journal of Intellectual Disability Research, 49, 657-671. 
Estes, A., Munson, J., Dawson, G., Koehler, E., Zhou, X., Abbott, R. (2009). Parenting stress and psychological functioning among mothers of preschool children with autism and developmental delay. Autism, 13, 375-387.

Hollingshead, A.B. (1975). Four factor index of social status. Unpublished manuscript, Yale University, NewHaven, CT.

Hoppes, K., \& Harris, S.L. (1990). Perceptions of child attachment and maternal gratification in mothers of children with Autism and Down syndrome. Journal of Clinical Child Psychology, 19, 365-370.

Jackson, C.T., Fein, D., Wolf, J., Jones, G., Hauck, M., Waterhouse, L., \& Feinstein, C. (2003). Responses and sustained interactions in children with mental retardation and autism, Journal of Autism and Developmental Disorders, 33, 115-121.

Kasari, C. \& Sigman, M. (1997). Linking parental perceptions to interactions in young children with autism. Journal of Autism and Developmental Disorders, 27, 39-57.

Kasari, C., Sigman, M., Mundy, P., \& Yirmiya, N. (1988). Caregiver interactions with autistic children. Journal of Abnormal Child Psychology, 16, 45-56.

Kasari, C., Sigman, M., \& Yirmiya, N. (1993). Focused and social attention of autistic children in interactions with familiar and unfamiliar adults - A comparison of autistic, mentally-retarded, and normal children. Development and Psychopathology, 5, 403-414.

Keen, D., Couzens, D., Muspratt, S., \& Rodger, S. (2010). The effects of a parentfocused intervention for children with a recent diagnosis of autism spectrum disorder on parenting stress and competence. Research in Autism Spectrum Disorders, 4, 229-241.

Landry, S.H., Garner, P.W., Pirie, D., \& Swank, P.R. (1994). Effects of social context and mothers' requesting strategies on Down's syndrome children's social responsiveness. Developmental Psychology, 30, 293-302. 
Lemanek, K.L., Stone, W.L., \& Fishel, P.T. (1993). Parent-child interactions in handicapped preschoolers - The relation between parent behaviors and compliance. Journal of Clinical Child Psychology, 22, 68-77.

Lord, C., Rutter, M., Dilavore, P., \& Risi, S. (1999). Autism Diagnostic Observation Schedule, Manual, Los Angeles, CA : Western Psychological Services.

Mahoney, G., \& Perales, F. (2005). Relationship-focused early intervention with children with pervasive developmental disorders and other disabilities: A comparative study. Journal of Developmental adn Behavioral Pediatrics, 26, 77-85.

Marfo, K. (1992). Correlates of maternal directiveness with children who are developmentally delayed. American Journal of Orthopsychiatry, 62, 219-233.

McHale, J.,Fivaz-Depeursinge, E., Dickstein, S., Robertson, J., Daley, M. (2008). New evidence for the social embeddedness of infants' early triangular capacities. Family Process, 47, 445-463.

McHale, S.M., \& Gamble, W.C. (1989). Sibling relationships of children with disabled and nondisabled brothers and sisters, Developmental Psychology, 25, 421-429.

McHale, S.M., \& Pawletko, T.M. (1992). Differential treatment of siblings in two family contexts. Child Development, 63, 68-81.

Meirsschaut, M., Roeyers, H., \& Warreyn, P. (2010). Parenting in families with a child with autism spectrum disorder and a typically developing child: Mothers' experiences and cognitions. Research in Autism Spectrum Disorders, 4, 661-669.

Meirsschaut, M., Roeyers, H. \& Warreyn, P. (2011). The social interactive behaviour of young children with autism spectrum disorder and their mothers: Is there an effect of familiarity of the interaction partner? Autism, 15, 43-64.

Montes, G. \& Halterman, J.S. (2007). Psychological functioning and coping among mothers of children with autism: A population-based study. Pediatrics, 119, e1040-e1046. 
Murphy, M., Bolton, P., Pickles, A., Fombonne, E., Piven, J., \& Rutter, M. (2000). Personality traits of the relatives of autistic probands. Psychological Medicine, 30, 1411-1424.

Noldus (2008). The Observer XT: The next generation of observation software. Wageningen, the Netherlands: Noldus.

Olsson, M.B., \& Hwang, C.P. (2001). Depression in mothers and fathers of children with intellectual disability. Journal of Intellectual Disability Research, 45, 535-543.

Plomin, R., Ashbury, K., \& Dunn, J. (2001). Why are children in the same family so different? Nonshared environment a decade later. The Canadian Journal of Psychiatry, 46, 225-233.

Quittner, A.L., \& Opipari, L.C. (1994). Differential treatment of siblings: Interview and diary analyses comparing two family contexts. Child Development, 65, 800-814.

Rao, P.A., \& Beidel, D.C. (2009). The impact of children with high-functioning autism on parental stress, sibling adjustment and family functioning. Behaviour Modification, 33, 437-451.

Rivers, J.W., \& Stoneman, Z. (2008). Child temperaments, differential parenting, and the sibling relationships of children with autism spectrum disorder. Journal of Autism and Developmental Disorders, 38, 1740-1750.

Rutgers, A.H., van IJzendoorn, M.H., Bakermans-Kranenburg, M.J., Swinkels, S., van Daalen, E., Dietz, C. et al. (2007). Autism, attachment and parenting: A comparison of children with autism spectrum disorder, mental retardation, language disorder, and nonclinical children. Journal of Abnormal Child Psychology, 35, 859-870.

Rutter, M., Le Couteur, A., \& Lord, C. (2003). Autism Diagnostic Interview Revised. Manual. Los Angeles: Western Pscyhological Services. 
Siller, M., \& Sigman, M. (2002). The behaviors of parents of children with autism predict the subsequent development of their children's communication. Journal of Autism and Developmental Disorders, 32, 77-89.

Spiker, D., Boyce, G.C., \& Boyce, L.K. (2002). Parent-child interactions when young children have disabilities. International Review of Research in Mental Retardation, 25, 35-70.

Taylor, H.B., Anthony, J.L., Aghara, R., Smith, K.E., \& Landry, S.H. (2008). The interaction of early maternal responsiveness and children's cognitive abilities on later decoding and reading comprehension skills. Early Education and Development, 19, 188-207.

Tellegen, P. Winkel, M., Wijnberg-Williams, B., \& Laros, J. (1998). Snijders-Oomen Niet-verbale Intelligentietest, SON-R 21/2-7. Swets \& Zeitlinger, B.V., Lisse, The Netherlands.

van IJzendoorn, M.H., Rutgers, A.H., Bakermans-Kranenburg, M.J., Swinkels, S.H.N., van Daalen, E., Dietz, C., et al. (2007). Parental sensitivity and attachment in children with autism spectrum disorder: Comparison with children with mental retardation, with language delays, and with typical development, Child Development, 78, 597-608.

Warreyn, P., Raymaekers, R., \& Roeyers, H. (2004). Handleiding Vragenlijst Sociale Communicatie. Destelbergen: SIG vzw.

Whiteman, S.D., McHale, S.M., \& Crouter, A.C. (2003). What parents learn from experience: The first child as a first draft? Journal of Marriage and the Family, 65, 608-621.

Willemsen-Swinkels, S.H.N., Buitelaar, J.K., \& van Engeland, H. (1997). Children with Pervasive Developmental Disorder, children with a language disorder and normally developing children in situations with high- and low-level involvement of the caregiver. Journal of Child Psychology and Psychiatry and Allied Disciplines, 38, 327-336. 
Table 1

Participant characteristics

\begin{tabular}{llll}
\hline & ASD $(\mathrm{n}=16)$ & TD $(\mathrm{n}=16)$ & \\
\hline $\begin{array}{l}\text { CA (months) } \\
\text { M(sd) }\end{array}$ & $68(11.56)$ & $48(13.02)$ & \\
$\begin{array}{l}\text { Range } \\
\text { Sex ratio (M:F) }\end{array}$ & $46-84$ & $29-67$ & $\chi^{2}(1)=1.25$ \\
$\begin{array}{l}\text { Total SCQ score } \\
\text { M(sd) }\end{array}$ & $12: 4$ & $9: 7$ & \\
Range & $18.60(6.19)$ & $4.17(3.05)$ & \\
& $10-29$ & $1-10$ & \\
$\begin{array}{l}\text { Word comprehension } \\
\text { (percentiles) }\end{array}$ & $36.69(37.95)$ & $54.581(27.73)$ & $F(1,30)=2.38$ \\
$\begin{array}{l}\text { M(sd) } \\
\text { Range }\end{array}$ & $1-99$ & $5-98$ & \\
$\begin{array}{l}\text { Developmental Age } \\
\text { (months) }\end{array}$ & & & \\
$\begin{array}{l}\text { M(sd) } \\
\text { Range }\end{array}$ & $64.97(20.11)$ & $51.29(17.78)$ & $F(1,30)=3.89$ \\
\hline $\begin{array}{l}\text { Note. CA = Chronological age, SCQ: Social Communication Questionnaire, Word comprehension obtained with } \\
\text { the PPVT, Developmental Age obtained with the SON-R }\end{array}$
\end{tabular}


Table 2

Means (standard deviations) for mother's initiatives and content of initiatives, and responsiveness and content of responses

\begin{tabular}{|c|c|c|c|c|c|c|c|}
\hline \multirow[b]{2}{*}{$\begin{array}{l}\text { Mother } \\
\text { Frequency }\end{array}$} & \multicolumn{2}{|c|}{ Child with ASD } & \multicolumn{2}{|c|}{ TD child } & \multirow{2}{*}{$\begin{array}{l}F \\
\text { diagnosis } \\
(1,15) \\
\left(\text { partial } \eta^{2}\right)\end{array}$} & \multirow{2}{*}{$\begin{array}{l}F \\
\text { context } \\
(1,15) \\
\left(\text { partial } \eta^{2}\right) \\
\end{array}$} & \multirow{2}{*}{$\begin{array}{l}F \\
\text { diagnosis*context } \\
(1,15) \\
\left(\text { partial } \eta^{2}\right)\end{array}$} \\
\hline & play & task & play & task & & & \\
\hline Initiatives (I) & $\begin{array}{l}69.38 \\
(25.64)\end{array}$ & $\begin{array}{l}87.06 \\
(32.14)\end{array}$ & $\begin{array}{l}74.75 \\
(25.13)\end{array}$ & $\begin{array}{l}92.31 \\
(28.30)\end{array}$ & $\begin{array}{l}1.65 \\
(.10)\end{array}$ & $\begin{array}{l}17.03^{* * *} \\
(.50)\end{array}$ & $\begin{array}{l}.00 \\
(.00)\end{array}$ \\
\hline \multicolumn{8}{|l|}{ Proportion } \\
\hline Declarative I & $\begin{array}{l}66.14 \\
(8.45)\end{array}$ & $\begin{array}{l}60.36 \\
(11.48)\end{array}$ & $\begin{array}{l}69.58 \\
(14.23)\end{array}$ & $\begin{array}{l}62.23 \\
(6.90)\end{array}$ & $\begin{array}{l}.74 \\
(.05)\end{array}$ & $\begin{array}{l}8.90 * * \\
(.37)\end{array}$ & $\begin{array}{l}.10 \\
(.01)\end{array}$ \\
\hline Imperative I & $\begin{array}{l}16.55 \\
(9.71)\end{array}$ & $\begin{array}{l}31.24 \\
(11.56)\end{array}$ & $\begin{array}{l}15.14 \\
(11.55)\end{array}$ & $\begin{array}{l}32.17 \\
(7.95)\end{array}$ & $\begin{array}{l}.01 \\
(.01)\end{array}$ & $\begin{array}{l}48.59 * * * \\
(.76)\end{array}$ & $\begin{array}{l}.37 \\
(.02)\end{array}$ \\
\hline Neutral I & $\begin{array}{l}17.31 \\
(10.69)\end{array}$ & $\begin{array}{l}8.41 \\
(4.92)\end{array}$ & $\begin{array}{l}15.28 \\
(7.58)\end{array}$ & $\begin{array}{l}5.60 \\
(3.62)\end{array}$ & $\begin{array}{l}1.7 \\
(.10)\end{array}$ & $\begin{array}{l}24.47^{* * * *} \\
(.62)\end{array}$ & $\begin{array}{l}.08 \\
(.01)\end{array}$ \\
\hline \multicolumn{8}{|l|}{ Probability } \\
\hline Responsiveness & $\begin{array}{l}.52 \\
(.09)\end{array}$ & $\begin{array}{l}.62 \\
(.16)\end{array}$ & $\begin{array}{l}.56 \\
(.12)\end{array}$ & $\begin{array}{l}.72 \\
(.13)\end{array}$ & $\begin{array}{l}10.59 * * \\
(.41)\end{array}$ & $\begin{array}{l}17.08^{* * *} \\
(.53)\end{array}$ & $\begin{array}{l}1.13 \\
(.07)\end{array}$ \\
\hline \multicolumn{8}{|l|}{ Proportion } \\
\hline Confirming & 85.91 & 83.26 & 86.11 & 80.41 & .08 & 1.05 & .11 \\
\hline Response (R) & $(11.73)$ & $(15.60)$ & (12.15) & (25.75) & $(.01)$ & $(.07)$ & $(.01)$ \\
\hline Non-confirming $\mathrm{R}$ & $\begin{array}{l}6.92 \\
(8.29)\end{array}$ & $\begin{array}{l}16.41 \\
(15.79)\end{array}$ & $\begin{array}{l}6.36 \\
(7.44)\end{array}$ & $\begin{array}{l}16.12 \\
(24.35)\end{array}$ & $\begin{array}{l}.01 \\
(.01)\end{array}$ & $\begin{array}{l}7.30 * \\
(.33)\end{array}$ & $\begin{array}{l}.001 \\
(.00)\end{array}$ \\
\hline Neutral R & $\begin{array}{l}7.17 \\
(9.15)\end{array}$ & $\begin{array}{l}.331 \\
(1.328)\end{array}$ & $\begin{array}{l}7.53 \\
(8.32)\end{array}$ & $\begin{array}{l}3.47 \\
(7.21)\end{array}$ & $\begin{array}{l}.59 \\
(.04) \\
\end{array}$ & $\begin{array}{l}15.00 * * \\
(.50)\end{array}$ & $\begin{array}{l}.79 \\
(.05) \\
\end{array}$ \\
\hline
\end{tabular}

Note. ${ }^{*} p \leq 0.05,{ }^{* *} p \leq 0.01,{ }^{* * *} p \leq 0.001$. 
Table 3

Means (standard deviations) for children's initiatives and content of initiatives, and responsiveness and content of responses

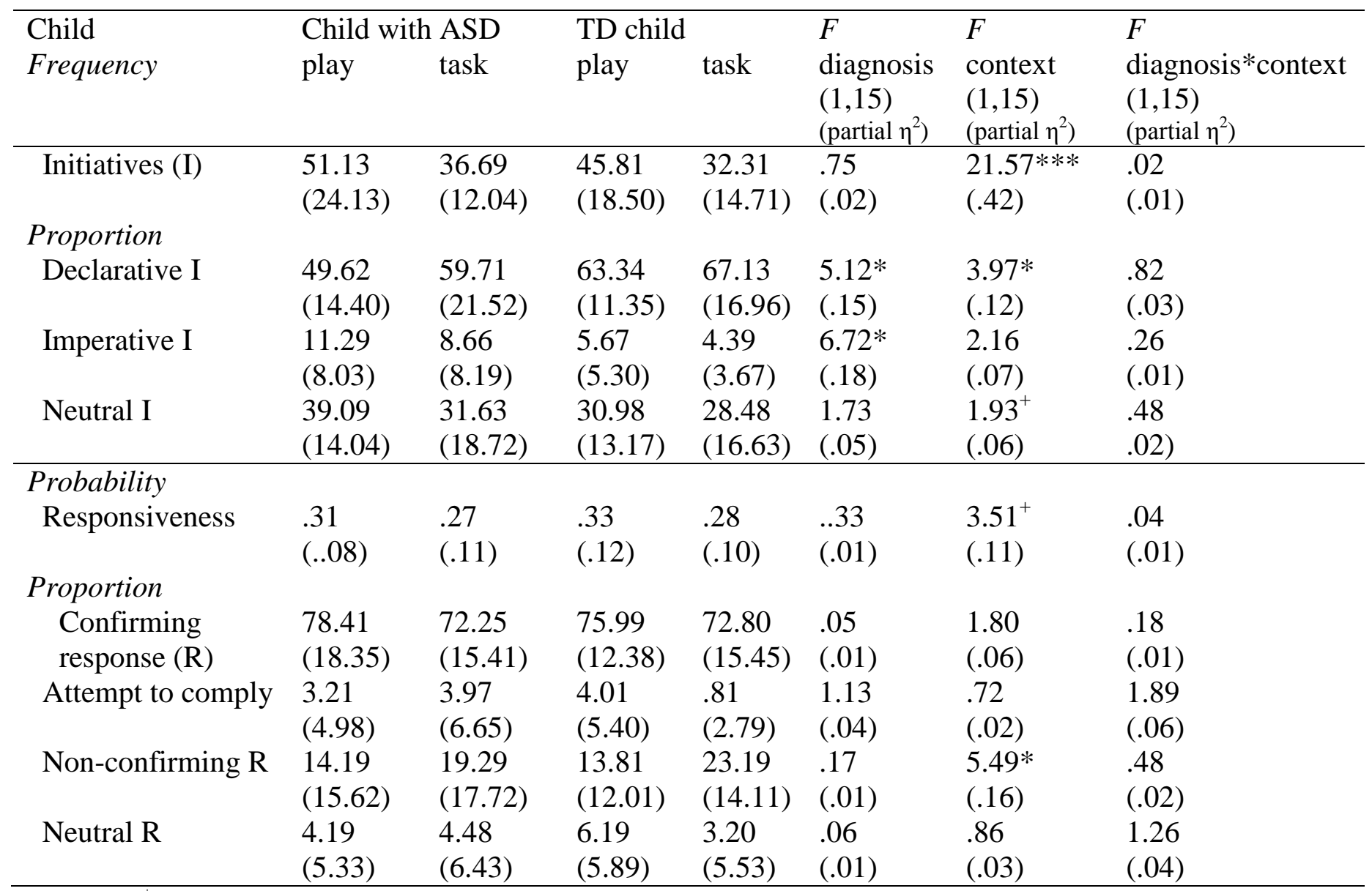

Note. ${ }^{+} p \leq 0.10,{ }^{*} p \leq 0.05,{ }^{* * *} p \leq 0.001$. 